\title{
Ponto Urbe
}

pontøurbe Revista do núcleo de antropologia urbana da USP

\section{Todo Paraiba é Ariano Suassuna: Go(N)Zo- Etnografia de uma Performance Paraibana}

\section{Cláudio Luiz Pereira}

\section{(2) OpenEdition}

Journals

\section{Edição electrónica}

URL: http://journals.openedition.org/pontourbe/1593

DOI: 10.4000/pontourbe.1593

ISSN: 1981-3341

\section{Editora}

Núcleo de Antropologia Urbana da Universidade de São Paulo

\section{Refêrencia eletrónica}

Cláudio Luiz Pereira, « Todo Paraiba é Ariano Suassuna: Go(N)Zo-Etnografia de uma Performance Paraibana », Ponto Urbe [Online], 6 | 2010, posto online no dia 31 julho 2010, consultado o 03 maio 2019. URL : http://journals.openedition.org/pontourbe/1593; DOI : 10.4000/pontourbe.1593

Este documento foi criado de forma automática no dia 3 Maio 2019

(C) NAU 


\title{
Todo Paraiba é Ariano Suassuna: Go (N)Zo-Etnografia de uma Performance Paraibana
}

\author{
Cláudio Luiz Pereira
}

Para Lara e Lisa, que se fizeram queridas.

1 Humor, poesia. Certa liberdade no falar, implícita no trato das coisas e nos fatos da vida, parece ser característica dos paraibanos. A Paraíba parece assim, vista num relance de poucos e memoráveis dias, um mundo emanado da alegoria, da auto-ironia, de um realismo fantástico, e de uma fantasia realística.

2 E lá estávamos nós, antropólogos de tempo integral, curiosos compulsivos e insaciáveis, em busca de tema ou de assunto. Seduzidos por um cartaz exposto na Universidade, sobre o dia da prostituta, e de uma "corrida da calcinha" (na qual os ganhadores receberiam de prêmio um bode para o primeiro lugar, duas galinhas e uma corda de caranguejo, para segundo e terceiro lugar, respectivamente), nos dispusemos a estar também lá, a ver e nos divertir, e quem sabe escrever aqui, para que a nossa experiência, humana demasiadamente humana, não se perca no buraco negro do contingente, e na obscura região do nosso esquecimento mais íntimo.

3 A Corrida da Calcinha é uma floresta de símbolos, e nela um antropólogo pode vagar de galho em galho e de assunto em assunto, como um macaco louco que provou de um fruto alucinógeno. Profusão de imagens, polifonia incontrolável, coro de contentes e descontentes, performance reveladora, bailado profundamente significativo na sua ordem de desordens. 


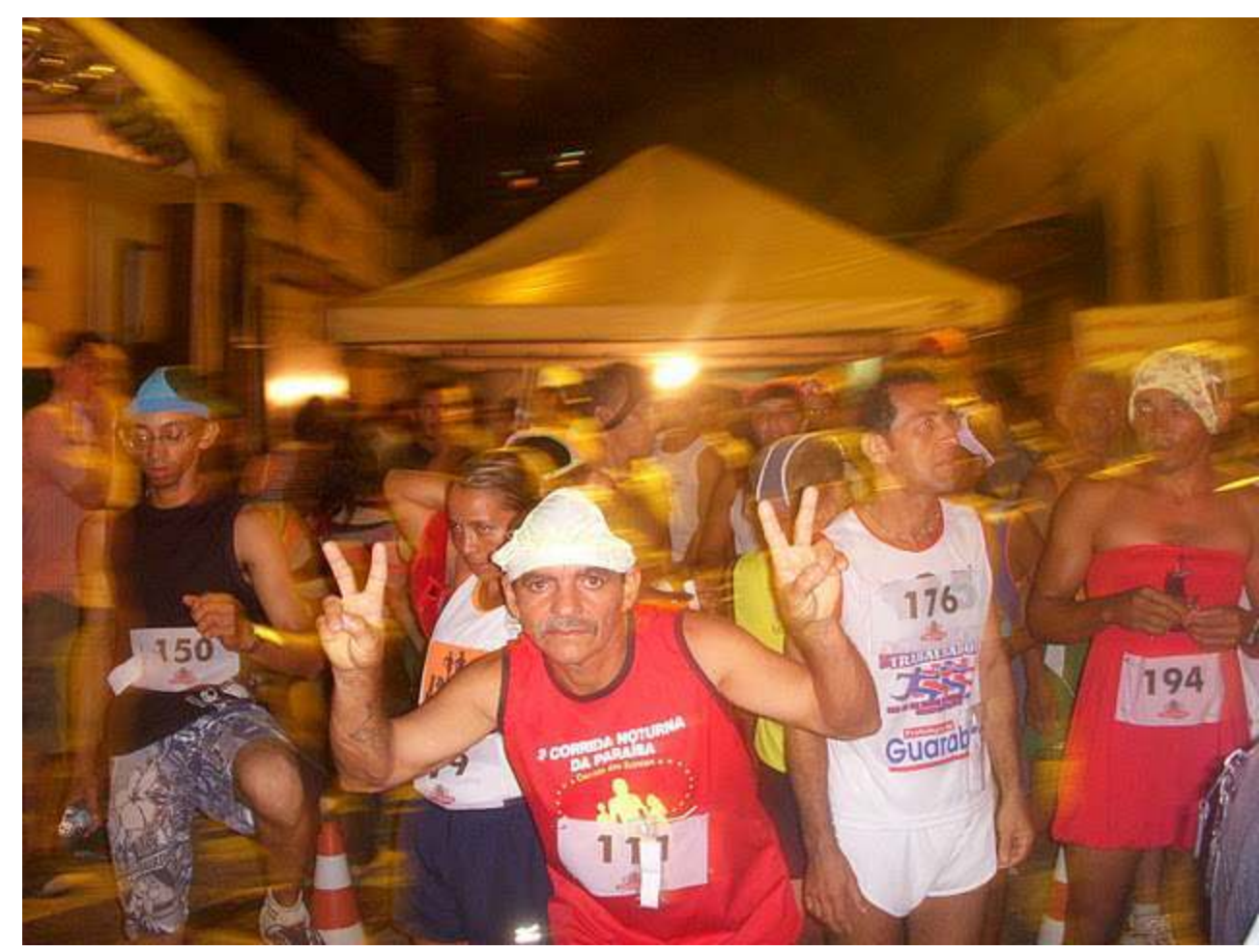

4 Tudo isto na Rua da Areia, cenário cinematográfico de filme B: cabarés, bregas, casas de famílias, comércios de porta de rua, bares, loja maçônica, boate com fachada de neon. Uma artéria da cidade onde talvez escorra lama, sangue, lágrimas, e sêmen humano. Meretrício de parcos méritos, com suas quengas gastas e gordas, outrora deve ter vivido certo apogeu, e agora definha, como um sintoma de decadência do centro da cidade. 0 puteiro é, pois, somente uma tatuagem que disfarça uma cicatriz no corpo urbano. Mas, lá ainda restam algumas meninas exuberantes, arrochadas nas suas roupas e maquilagem espalhafatosas, com olhares que revelam a inocência perdida, e uma força de atração que conduz o olhar dos homens, que quando elas passam, coçam seus paus por cima da calça, com sorrisos safados. Olhares libidinosos são quase sempre cheios de reciprocidade.

Duas tendas demarcavam a arena performática. Na primeira, antecedida por dois cartazes artísticos (Mostra Puta Arte) que sinalizavam e embelezavam o lugar, se encontram alguns estandes onde eram distribuídos folhetos sobre AIDS e contra a violência sexista, venda de camisetas alusivas ao evento, aparato de cadeiras e macas para a realização de massagens, e algumas mesas com produtos alimentícios que deveriam ser distribuídos entre os inscritos para a corrida: melancia talhada, mugunzá de milho, água e refrigerante. Na última tenda, via-se uma exposição de fotografias, com rostos disformes e ampliados. Esta tenda, inclusive, ficava frente a um bar onde se projetava, no seu interior, o making of da Playboy, feito com a modelo Viviane Araújo.

Dois locutores narram o evento: o primeiro, de chapéu de palha e bigode plástico, a partir do palco ordena, diz o que vai acontecer, faz pilheria com a platéia, provoca, dá ênfase com o humor, esculhamba, faz escárnio. Ele explica o porquê do dois de junho ser aquela data comemorada. Alude a greve de sexo das prostitutas francesas, em 1972, e a institucionalização desta data como dia internacional da prostituta. $O$ segundo, mais sério e diligente, entrevista algumas personalidades presentes, como a presidente da associação de Prostitutas de João Pessoa, ou os corredores. Atrás deles, um Dj toca uma música de Zé Ramalho: "Dê-me seu dinheiro que eu quero viver...". 
7 Entre as duas tendas, quando chegamos, concentravam-se os participantes da corrida, todos eles portando uma calcinha na cabeça (o locutor avisa a um concorrente que não pode ser cueca, tem que ser calcinha mesmo!). A maior parte com a peculiar cara dos nordestinos, larga para caber um sorriso extenso. No meio do grupo, um estrangeiro alucinado de tão animado, bem como algumas poucas mulheres, parte delas já na terceira idade (quando da premiação por faixa etária descobriu-se que ninguém ganhou nas faixas inferiores entre 39 e 49 anos), e dois cadeirantes com calcinhas na cabeça com bandeirinhas do Brasil. A prova era patrocinada pela Associação de Prostitutas de João Pessoa e Federação Paraibana de Atletismo.

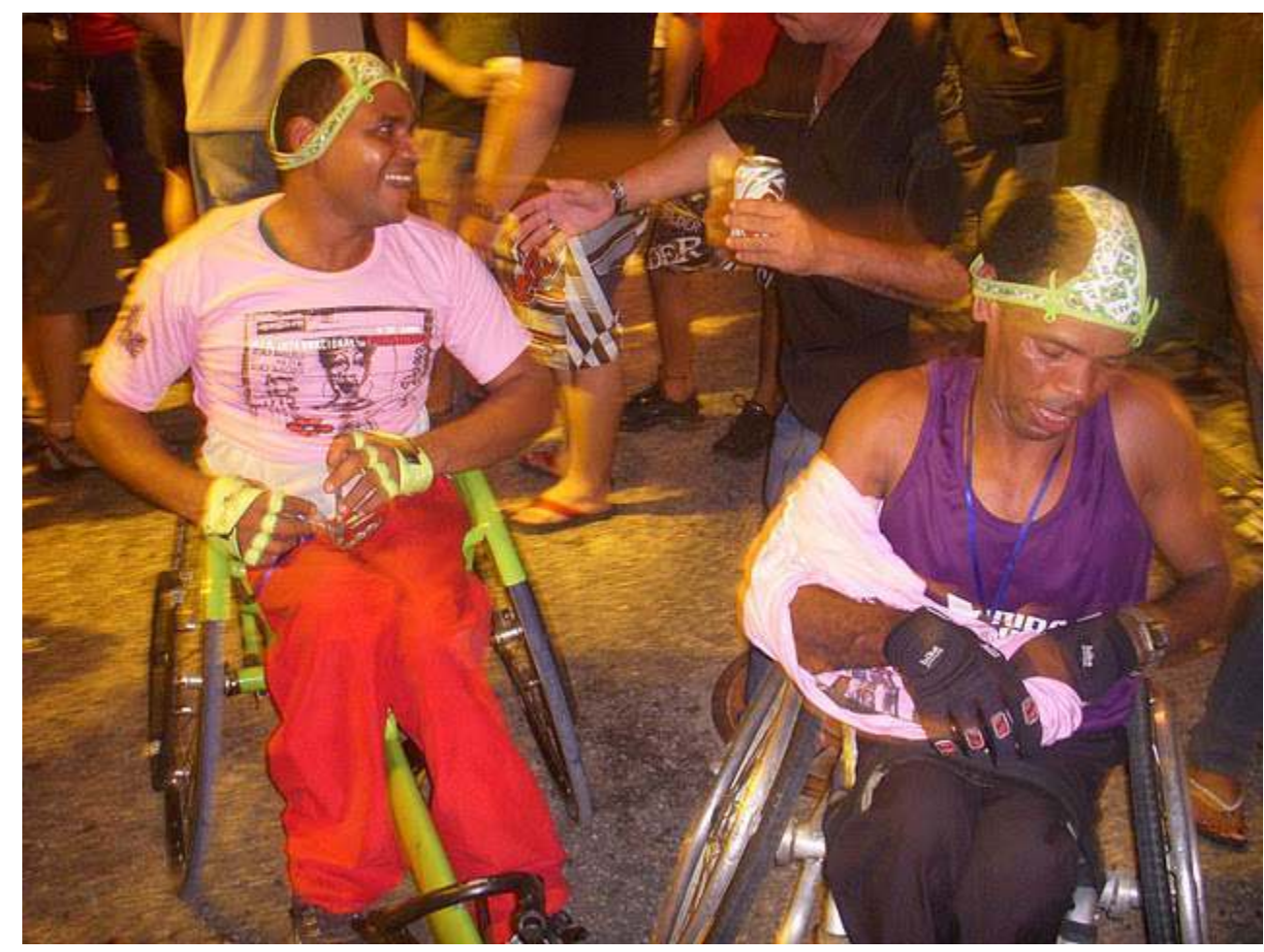

8 A corrida estava marcada para começar às dezenove horas e dois minutos. O percurso seria curto, não mais que dois quilômetros, mas uma poderosa ladeira desafiaria os concorrentes. Um ribombar de foguetes e morteiros sinalizou a partida, que, aliás, foi queimada, como um fluxo de ejaculação precoce, por uns poucos ansiosos pela vitória, e por muitos outros exibidos, diante da cobertura do evento feito por uma equipe do Pânico na TV.

9 E lá foram os corredores, a partir da Boate Scala, perdendo-se na penumbra de uma paisagem mal iluminada, de onde só retornariam cinco minutos depois e, pelo lado oposto da rua. Briosos os primeiros, ofegantes os retardatários, todos pareciam felizes com a confortadora sensação do dever cumprido; e, no decorrer da noite, todos sustentariam suas medalhas de participante com o orgulho saliente dos que se superam.

10 A cerimônia de premiação, aliás, foi mais importante do que a corrida, que só foi experimentada mesmo por quem correu (Além de um motoqueiro que antecedia os corredores, fazendo-se de abre-alas.). Em frente ao palco ficava o pódio. Primeiro os ganhadores receberam os troféus, e depois os prêmios, agora já sobre o pódio e com grande estardalhaço do público. Um dos patrocinadores comprou o bode destinado à vencedora feminina (o locutor anunciou uma buchada para o dia seguinte!). o prêmio mais difícil de receber foi a corda de caranguejo, que nem era caranguejo e sim gaiamum. 
Perguntei-me o que estes animais pensariam de toda aquela atividade humana: as galinhas pareciam curiosas, os bodes pareciam resignados (talvez fossem expiatórios mesmos), e os caranguejos estavam alertas e combativos, como é do seu mister. Soube-se, enfim, que o ganhador tinha vindo da cidade de Pilar, e a ganhadora é apresentada como uma índia potiguar. Ou seja, um era de Alagoas, e a outra do Rio Grande do Norte.

11 A animação se mantém após a corrida, na medida em que já desponta na rua a ala dos Ursos Amigos: o primeiro denominado de Batucada, com seus repiques de tambores, surdos e tamborins, e seu grito de guerra particular (Batucada!), precedida de figuras do bumba-meu-boi, palhaço de perna de pau, estandarte, porta-bandeira bem másculo; o segundo, denominado Panda, com seus dois ursos jeitosos e mal amanhados, como que suspensos por invisíveis fios puxados por mãos laboriosas, a trocar gestos lúbricos com um porta-bandeira viadíssimo.

No palco as atrações se sucedem. Uma banda de pagode. Uma banda de Axé. No chão um grupo de três jovens encena a coreografia de rebolation. Sentiam-se, quiçá, Robinho, Ganso e Neymar. Uma Drag, com visual de ninfeta, sobe ao palco e dubla uma música ingênua com gestos obscenos: com mãos que indicam um portentoso falo cada vez que a música pronunciava a palavra amor, e com uma língua sibilante de cobra cascavel direcionada aos espectadores. Lady Gaga do agreste, desafiante, diante de um bêbado que, na frente do palco, a provoca. A platéia pede bis (Mais tarde, ao cumprimentá-la pelo show, ela mostrou-se tímida e recatada). Já os punks, todos vestidos de preto, sentam-se no chão e bebem uma garrafa de Martini. Um casal entrelaça-se, corpos unidos por um laço de passionalidade. A polícia passa. As putas passam em grupos, para cima e para baixo e param nas portas de seus bordéis. Algumas crianças passam. O Juizado de menores também passa. Alguns travestis, alguns transexuais. Jornalistas. Estudantes de ciências sociais e artes. Gente do lugar, moradores antigos. Corpos dançam desconjuntados. As pessoas parecem alegres e divertidas. Alguém anuncia que num cabaré tal está tendo um forró gostoso. Agora, também, é possível ver professores universitários que tinham vindo à cidade para um congresso de arquitetura. Uma menina anota num caderno (pergunto se ela é estudante de antropologia, ela me diz que é jornalista cobrindo o evento). Muitos fotógrafos, profissionais e amadores, retêm os momentos. Como retratar a dimensão do onírico? Pergunto-me eu desesperançado. O comércio de alimentos e bebida cresce, junto com o cheiro de lingüiça calabresa, expostas como membros masculinos decepados. Um grupo de garis invade o cabaré verde incandescente como uma turba alegre, e carrega sobre os ombros uma puta simpática que ri e acena. Lá fora, uma moça aparece portando um berimbau. Um poeta desbocado declama versos descarados. Outro rapaz demonstra habilidade com malabares. Sons de guitarra incendeiam o lugar. Rock denso agora vindo do bar. Música pesada, mas redondinha. Meninas bonitas na porta, gente jovem que aprecia o mistério e a grandeza da noite. No fim, ainda veríamos um maracatu: ritmado, solene, a última caravana que passa com destino ao fim dos tempos. 


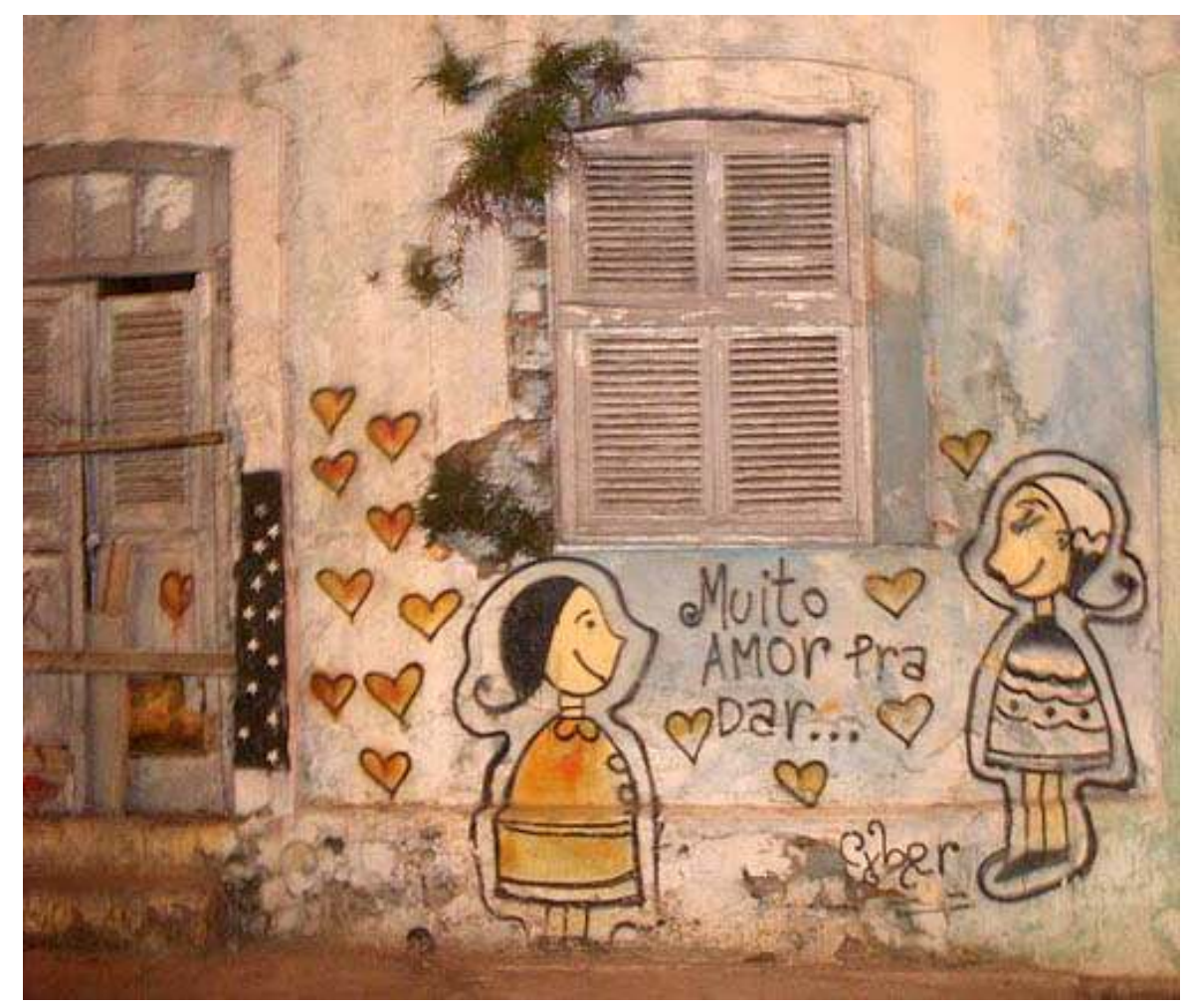

13 À meia-noite, segundo foi anunciado, aconteceria, também, um desfile de lingerie na Boate Scala. A calcinha, como sabemos, é prenhe de interesse humano. Símbolo, vestuário e fetiche, ela disfarça e revela, oculta e mostra contornos, evoca lascívias e prazeres. Fazer uma corrida a tendo como mote revela um humor primoroso. Faz-nos rir, pois o riso também é gozo sexual, provoca nossos pensamentos mais recônditos, atiçando assim a curiosidade popular. $\mathrm{E}$, de qualquer modo, sustenta um interesse pedagógico por questões muito sérias, e que deveriam conformar nossa noção de cidadania, sobretudo, aqui, sob a imperativa violência contra a mulher em uma sociedade que se sabe machista. Talvez, por isto mesmo, as chamadas desta quarta Corrida da Calcinha e deste sexto ano de comemoração do Dia Internacional da Prostituta, na Paraíba, são mais que explícitas. Expressões como "Somos o que somos", "Mulheres são iguais em qualquer profissão", "A arte ocupa espaço como forma de transformação e evolução" foram reiteradamente enfatizadas, e revelaram uma preocupação social pungente: há que se ser tolerante e respeitoso com a vida no que ela tem de diferente e diverso; e há que se aceitar que as prostitutas (das sacerdotisas de antigamente às garotas de programas de agora, das quengas populares às putas de luxo) deveriam gozar mais do que de um merecido direito à felicidade infindável. 


\section{AUTHOR}

\section{CLÁUDIO LUIZ PEREIRA}

Cláudio Luiz Pereira é Antropólogo da Universidade Federal da Bahia. 